\title{
Three-Dimensional Finite-Element Analysis of Immediate Loading Dental Implants"
}

\author{
Giampietro PISCOPO ${ }^{* *}$, Eugenio PEZZUTI ${ }^{* *}$ and Pier Paolo VALENTINI ${ }^{* *}$ \\ **Department of Mechanical Engineering \\ University of Rome "Tor Vergata" \\ Via del Politecnico, 1 - 00133 - Rome - Italy \\ E-mail: piscopo@ing.uniroma2.it; pezzuti@mec.uniroma2.it; valentini@ing.uniroma2.it
}

\begin{abstract}
In this paper a complex prosthesis of dental implants, inserted in a mandible bone, has been analyzed using a virtual model. The study has been performed by means of a three-dimensional finite element model including the implants, the bridging structure and the bone. The interaction between implant screws and bone has been simulated in detail. Four different load conditions has been implemented to mimic the masticatory phase. The stress distribution in the implants and in the bone has been evaluated. Effects of possible temperature variation and assembling errors have been also taken into account. Moreover, the stiffening effect of the stabilizing bar that connect the implants has been also discussed. Starting from the results of the numerical investigations an optimization of the shape of the implants has been proposed in order to optimize the assembling procedure.
\end{abstract}

Key words: Dental Biomechanics, Immediate Loading Implants, Virtual Model, Finite Element Modeling

\section{Introduction}

The clinical therapy for treating patients with missing teeth has been significantly improved by modern implant methods. The prosthesis supported by implants have become an integral part of restorative therapy for both completely and partially edentulous patients ${ }^{1,2)}$.

Among the most used types of implant there are the monophasic and the biphasic solutions. The monophasic implants are also called "immediate loading implants" because they allow a reduced time for patient follow-up. The implants are classified by geometrical features (like length and diameter) and by the number of the treads. The screws are connected together with an electro welded bar. The bar ensures the main stability of the implants until the osseointegration occurs. The dentist can choose the better solution according to the patient situation. Among the reasons of their success there is the possibility to have a masticatory ability, by the use of a provisional prosthesis, few hours after the insertion of the implants. During the first months a provisional prosthesis is needed until the complete osseointegration occurs, and then the final prosthesis can be mounted. Today the use of immediate loading implants provides excellent long-term results ${ }^{3-5)}$. On the other hand, this intensive use is not supported by a standardization of main components. Moreover the performances of the implants, under different loading conditions, are not well 
known.

In the natural dentition, the periodontal ligament has the capacity to absorb stress and allow tooth movements; this is not possible in the bone-implant interface due to the abnormal stiffness ${ }^{6}$. Load transfer at the bone-implant interface depends on several factors: the type of loading ${ }^{7,8)}$, the material properties of the implant and prosthesis ${ }^{9,10}$, the nature of the bone-implant interface ${ }^{11)}$, the quality and quantity of the surrounding bone ${ }^{12,13)}$, the implant geometry (i.e. length, diameter and shape) and the implant surface structure ${ }^{14,15)}$. If the force exceeds the capacity of the interface to absorb stress, the implant will fail ${ }^{16-18)}$. The stress distribution can be also correlated to inflammatory phenomena and to bone recession, possible causes of the failure of the implant ${ }^{19,20}$. Another problem is the necessity to align the upper parts of the implants after the insertion, because the screw, during its insertion, follows the hole of the extracted tooth. This alignment is necessary to assemble correctly the final prosthesis. The operation is difficult and its success and accuracy depends on the ability of the dentist. For all these reasons, an investigation on the bone-implant biomechanics can be useful to improve the reliability and performance of the restorative treatments and this consideration is the main motivation of the presented study. Virtual engineering has revealed to be a valid instrument to compute biomechanics aspects in an objective way, giving important information about the implant-bone interaction and mechanical properties of the structures. Several three dimensional Finite Element Models of complex implants, inserted in the bone, have been built. The Finite Element technique has been successfully used in previous studies in order to investigate stress and deformation of the structures ${ }^{21-24)}$. Recently, stress distribution in bone correlated with implants has been studied by means of both two dimensional (2D) and three dimensional (3D) finite element models. Studies comparing the accuracy of these analyses found that, if the shapes are complex and detailed stress information is required, then $3 \mathrm{D}$ modeling is necessary ${ }^{25)}$. The virtual models can perform many preliminary analysis without any risk for the patient saving costs and time. Of course a virtual model cannot completely replace a clinical experimentation, but it contributes to the initial decisional phases.

In this paper the stresses occurring during masticatory phase have been evaluated taking into account different loading conditions. The effect of temperature variation and the assembly errors have been analyzed as well. To simplify the assembly procedure the effect of the removal of the connecting bar has been also studied. Starting from the results coming from the virtual models, a new geometry of the upper part of the implant has been proposed in order to minimize the assembly errors.

\section{Materials and Methods}

A real clinical case of a patient with full edentulism has been modeled. The structure, shown in Figure 1, has 11 screws, connected by an electro-welded bar with circular cross section of $1.5 \mathrm{~mm}$ diameter. The geometrical properties of implants are summarized in table 1.

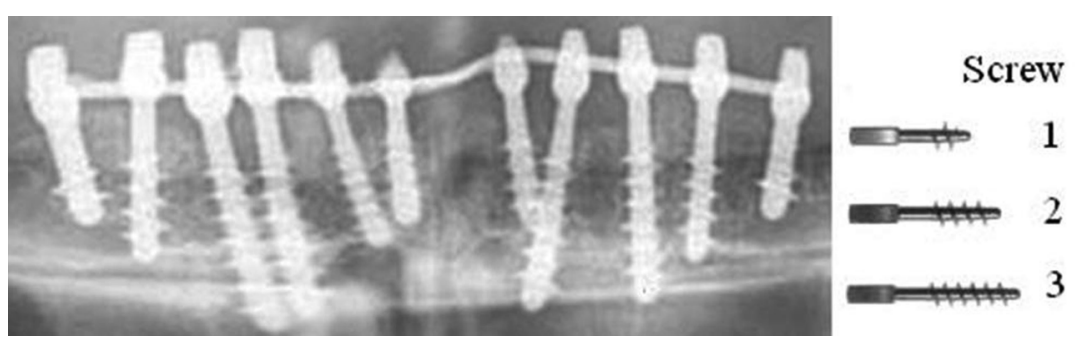

Figure 1. Post surgery image of implants 
Table 1. Geometrical properties of implants

\begin{tabular}{|l|l|l|l|l|}
\hline Screw type & ext. $\varnothing$ & int. $\varnothing$ & coils \# & length \\
\hline 1 & $5 \mathrm{~mm}$ & $2,25 \mathrm{~mm}$ & 2 & $11,5 \mathrm{~mm}$ \\
\hline 2 & $4 \mathrm{~mm}$ & $2,25 \mathrm{~mm}$ & 4 & $16 \mathrm{~mm}$ \\
\hline 3 & $4 \mathrm{~mm}$ & $2,25 \mathrm{~mm}$ & 6 & $20,5 \mathrm{~mm}$ \\
\hline
\end{tabular}

Each part of the implant (screws, upper structure and bones) have been virtually reconstructed by means of a parametric CAD software and have been simulated using finite elements technique. On the left side of Figure 2 the full 3D model of the solution is shown; on the right side, the connection between implants and mandible bone is shown. The bone has been split into the hard cortical zone that forms the shell of the jaw, and the trabecular (spongy) bone inside. The thickness of the cortical part and the consistency of the spongy have been assumed from literature ${ }^{27,28)}$. Cement thickness layer has been ignored. The implants have been positioned to simulate the mono and bi-cortical conditions. A fixed connection between the bone and implants along the interface has been assumed.

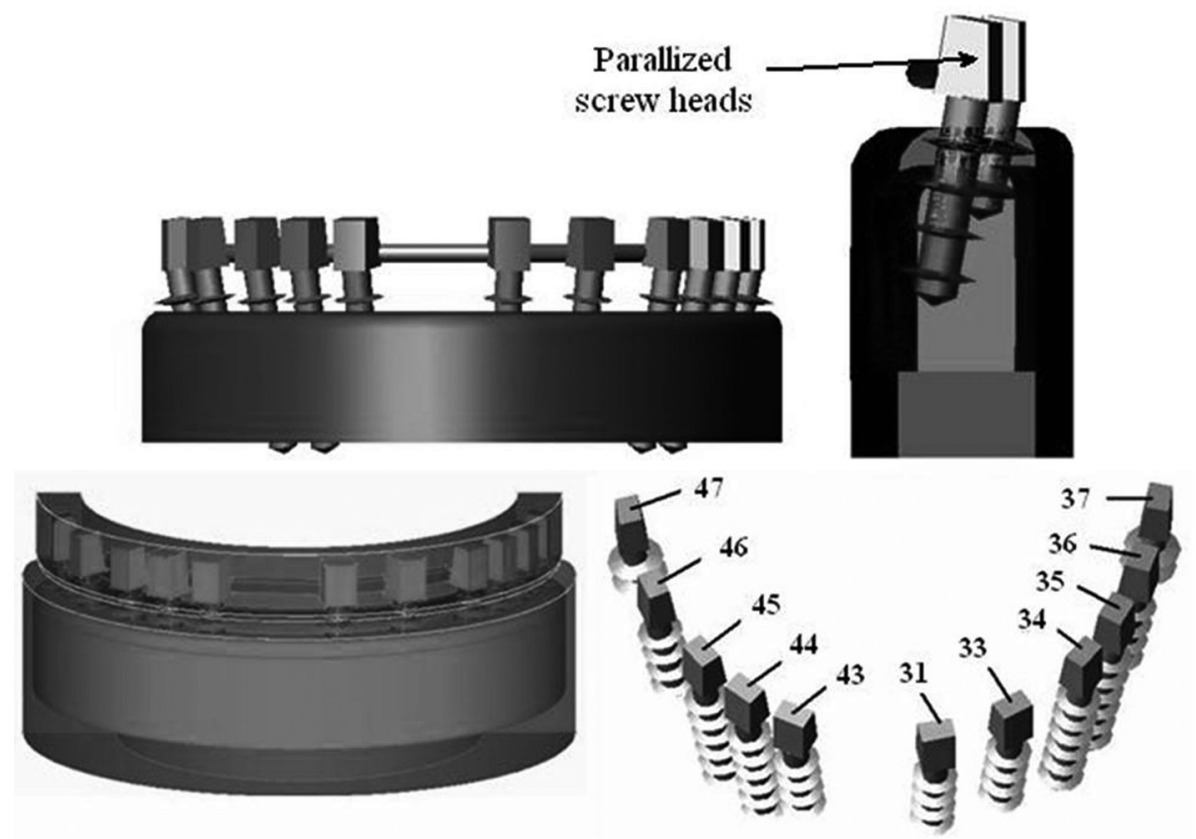

Figure 2. Complete three dimensional virtual model and implants nomenclature.

The geometry of the screw threads has been modeled both with an accurate model and with a simplified one (using symmetry and neglecting the helical pitch). Models of single screw, with symmetrical and helical threads, has been studied and the results have been compared to the Maduschka's observations ${ }^{29}$. The results of the two approaches are similar and in good accordance to the analytical theory so, in order to simplify the model and to reduce the computation time, the symmetrical FE model of the screw has been used. The contact between screws and bone has been simulated with a direct connection between the nodes on the surfaces of the threads and the corresponding nodes on the bone. The generation of a congruent mesh ensures that the nodes on the two contact surfaces are coincident. In this way it is possible to simulate different levels of osseointegration, merging or not the coincident nodes (merging all nodes for the perfect osseointegration or a part of them for a partial osseointegration). Different levels of osseointegration have been simulated on a single screw bone connection. The simulations of $100 \%$ and $60 \%$ osseointegration produce comparable stress fields. Some differences can be noted near the 
first thread, under the screw head where the less integrated implant causes an higher stress (less than $10 \%$ ).

Finally, in order to complete the 3D model (Figure 2, below), an upper structure, that reproduces the entire set of teeth, has been included. Two kinds of structure have been modeled: a temporary ceramic one used until the fully osseointegration occurs, and a final one. The aesthetic coating, not necessary for subsequent analyses, has not been modeled in order to reduce the computational complexity.

The finite element model has been built using 350000 tetrahedral solid elements with 10 nodes each.

All materials have been assumed to have a linear elastic, homogeneous, and isotropic behavior. The corresponding elastic properties, such as Young's modulus (E), Poisson ratio $(v)$, linear thermal expansion coefficient $(\alpha)$ are summarized in Table $2^{30-32)}$.

Table 2. Properties of materials

\begin{tabular}{|l|c|l|l|}
\hline Material/part & $E(\mathrm{MPa})$ & $v$ & $\alpha(1 / \mathrm{K})$ \\
\hline Titanium (screws and bar) & 110000 & 0,34 & $8,4 \mathrm{e}-6$ \\
\hline Cortical bone & 17000 & 0,3 & $2,7 \mathrm{e}-5$ \\
\hline Spongy bone & 225 & 0,33 & $2,2 \mathrm{e}-5$ \\
\hline
\end{tabular}

Different load conditions have been simulated. The masticatory phase has been split into four different load conditions, symmetrical and not symmetrical, reported in Figure 3.
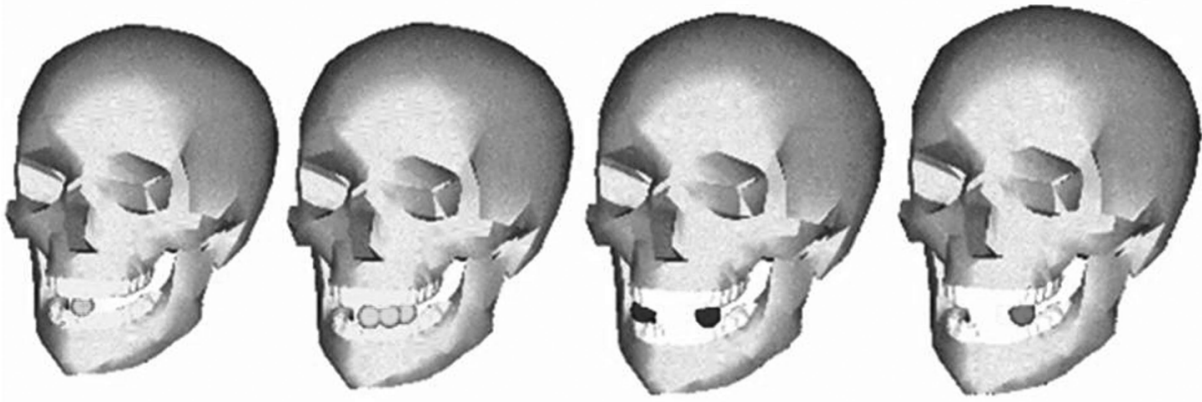

Figure 3. Four masticatory load sets

The following average masticatory forces, with a natural direction with respect to the occlusal plane have been included in the model ${ }^{7,16,26,33)}$ :

1. Masticatory load set 1: structure is loaded with an axial force of $F z=-60 \mathrm{~N}$ and a radial force of $F r=60 \mathrm{~N}$ on the central incisive. Lateral incisive is loaded with a $F z=-20 \mathrm{~N}$ and $F r=10 \mathrm{~N}$.

2. Masticatory load set 2: canine is loaded with $F z=-50 \mathrm{~N}$ and $F r=7 \mathrm{~N}$. First premolar is loaded with $F_{z}=-150 \mathrm{~N}$ and $F r=7 \mathrm{~N}$, while second premolar is loaded with $F z=250 \mathrm{~N}$ and $F r=10 \mathrm{~N}$.

3. Masticatory load set 3: on one mouth side is applied a total force of $F z=200$ N, on the other side is applied $F z=150 \mathrm{~N}$. Then, all three molar and two premolar are loaded with $F z=40 \mathrm{~N}$ on the first side, and with $F z=30 \mathrm{~N}$ on the second side.

4. Masticatory load set 4: the entire load of $F z=-400 \mathrm{~N}$ is applied on the second premolar.

Moreover the effect of thermal gradients, simulating the presence of cold or hot food, has been evaluated. For the hot food the temperature of implants has been set to $42{ }^{\circ} \mathrm{C}$ and the temperature of the bone to $36^{\circ} \mathrm{C}$; for the cold food the temperature of implants has been set to $0{ }^{\circ} \mathrm{C}$ and the temperature of the bone to $36^{\circ} \mathrm{C}$.

Moreover, assembly errors have been simulated in order to investigate the effects of 
misalignments on the entire structure. On the screws \#44 and \#34 (Figure 2), corresponding to the first premolar, $10 \mu \mathrm{m} \div 15 \mu \mathrm{m}$ assembling errors have been imposed.

\section{Results}

Table 3 summarizes the results of the four simulations with the loading conditions in the previous section. The maximum stresses in the implants are presented.

Table 3. Maximum stress level during masticatory phase

\begin{tabular}{|c|c|c|c|c|c|}
\hline $\begin{array}{c}\text { Load } \\
\text { Set }\end{array}$ & \multicolumn{2}{|c|}{ Screw } & $\begin{array}{c}\text { Upper } \\
\text { structure }\end{array}$ & Cortical & Spongy \\
\hline 1 & $\# 31$ & $90 \mathrm{MPa}$ & $30 \mathrm{MPa}$ & $70 \mathrm{MPa}$ & $18 \mathrm{MPa}$ \\
\hline 2 & $\# 34$ & $70 \mathrm{MPa}$ & $35 \mathrm{MPa}$ & $40 \mathrm{MPa}$ & $30 \mathrm{MPa}$ \\
\hline 3 & $\# 47$ & $25 \mathrm{MPa}$ & $10 \mathrm{MPa}$ & $20 \mathrm{MPa}$ & $10 \mathrm{MPa}$ \\
\hline 4 & $\# 35$ & $50 \mathrm{MPa}$ & $40 \mathrm{MPa}$ & $35 \mathrm{MPa}$ & $22 \mathrm{MPa}$ \\
\hline
\end{tabular}

The nodes with the maximum stress are located around the implant neck, near the first screw thread. The fourth load test is the most onerous, since it concentrates an high force only on one side of the structure (Figure 4).
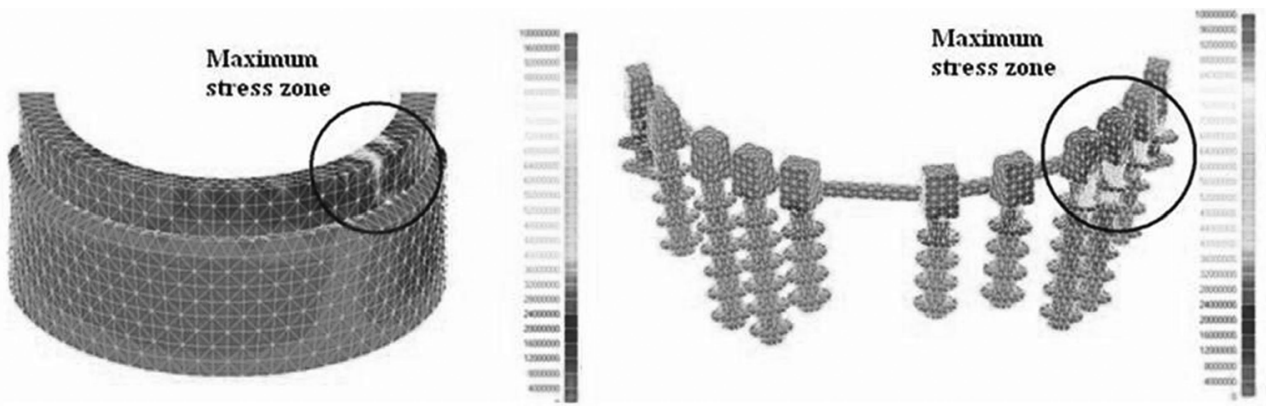

Figure 4 . The entire system and screws detail, loaded with the 4th masticatory set.

The force is applied to the implant \#35 (see Figure 5). A part of the load is well distributed also on screws \#33,\#36 and \#37. This effect is caused by the upper structure and by the titanium bar. They involve the nearest implants on the distributions and absorbing of the loads.
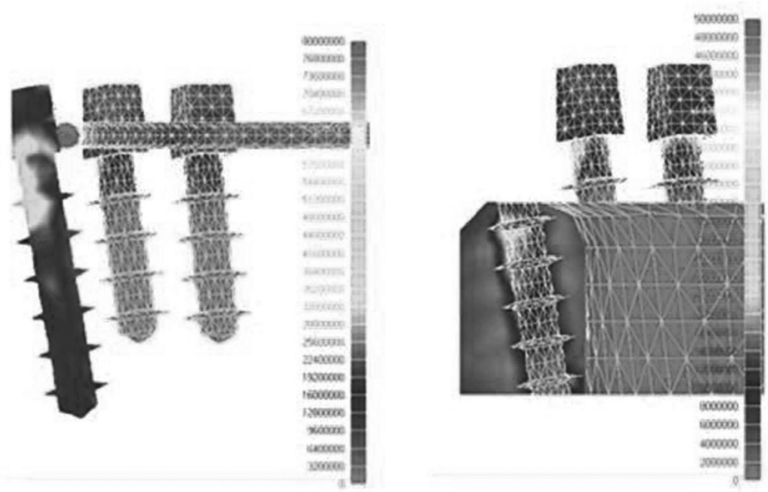

Figure 5. Cross section of the thirty-fifth screw implant 
Thermal variations illustrated in the previous section of the paper have been analyzed to simulate the presence of hot and cold foods or drinks. An example of the stress distribution is shown in Figure 6 and all the results are summarized in Table 4.
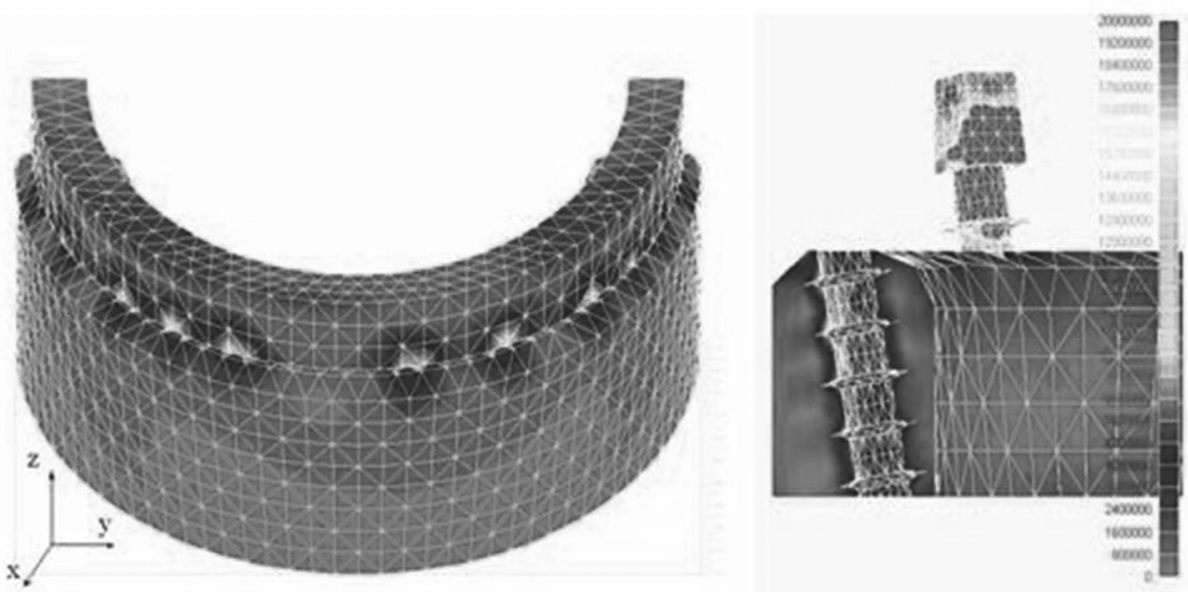

Figure 6. The entire system and a cross section at the screw \#34, hot food simulated.

Table 4. Maximum stress level computed with the thermal analysis.

\begin{tabular}{|l|l|l|l|l|l|}
\hline$\Delta \mathrm{T}$ & \multicolumn{2}{|l|}{ Screw } & Upper structure & $\begin{array}{l}\text { Cortical } \\
\text { bone }\end{array}$ & $\begin{array}{l}\text { Spongy } \\
\text { bone }\end{array}$ \\
\hline$+6{ }^{\circ} \mathrm{C}$ & $\# 35$ & $9 \mathrm{MPa}$ & $6 \mathrm{MPa}$ & $5 \mathrm{MPa}$ & $1 \mathrm{MPa}$ \\
\hline$-36^{\circ} \mathrm{C}$ & $\# 34$ & $60 \mathrm{MPa}$ & $50 \mathrm{MPa}$ & $32 \mathrm{MPa}$ & $8 \mathrm{MPa}$ \\
\hline
\end{tabular}

Moreover, assembly errors have been simulated in order to investigate the effects of screw heads misfits. Errors on screws \#44 and \#34, corresponding to the first premolar, have been considered. For screw \#44, the enforced displacement is along horizontal direction, while for screw \# 34 is along vertical direction. The results are reported in Table 5 and summarized in Figure 7.

Table 5. Stress levels for simulated misfits.

\begin{tabular}{|c|c|c|c|c|c|}
\hline $\begin{array}{c}\text { Error (enforced } \\
\text { displacement) }\end{array}$ & \multicolumn{2}{|c|}{ Screw } & $\begin{array}{c}\text { Upper } \\
\text { structure }\end{array}$ & $\begin{array}{c}\text { Cortical } \\
\text { bone }\end{array}$ & $\begin{array}{c}\text { Spongy } \\
\text { bone }\end{array}$ \\
\hline $10 \mu \mathrm{m}$ & $\# 44$ & $12 \mathrm{MPa}$ & $13 \mathrm{MPa}$ & $8 \mathrm{MPa}$ & $2 \mathrm{MPa}$ \\
\hline $10 \mu \mathrm{m}$ & $\# 34$ & $20 \mathrm{MPa}$ & $20 \mathrm{MPa}$ & $18 \mathrm{MPa}$ & $4 \mathrm{MPa}$ \\
\hline $15 \mu \mathrm{m}$ & $\# 44$ & $16 \mathrm{MPa}$ & $17 \mathrm{MPa}$ & $10 \mathrm{MPa}$ & $3 \mathrm{MPa}$ \\
\hline $15 \mu \mathrm{m}$ & $\# 34$ & $30 \mathrm{MPa}$ & $28 \mathrm{MPa}$ & $26 \mathrm{MPa}$ & $7 \mathrm{MPa}$ \\
\hline
\end{tabular}

The more stressed zone is within the cortical bone, near the screw \#34 and near the first thread of the screw which is inserted in the bone. Actually this level of stress can be reduced by the physiological adaptability of the bone, during the life of the implants. Even though the level is low, the stress is constant and can cause tissue inflammation and can be related to bone recession phenomena ${ }^{20)}$. 


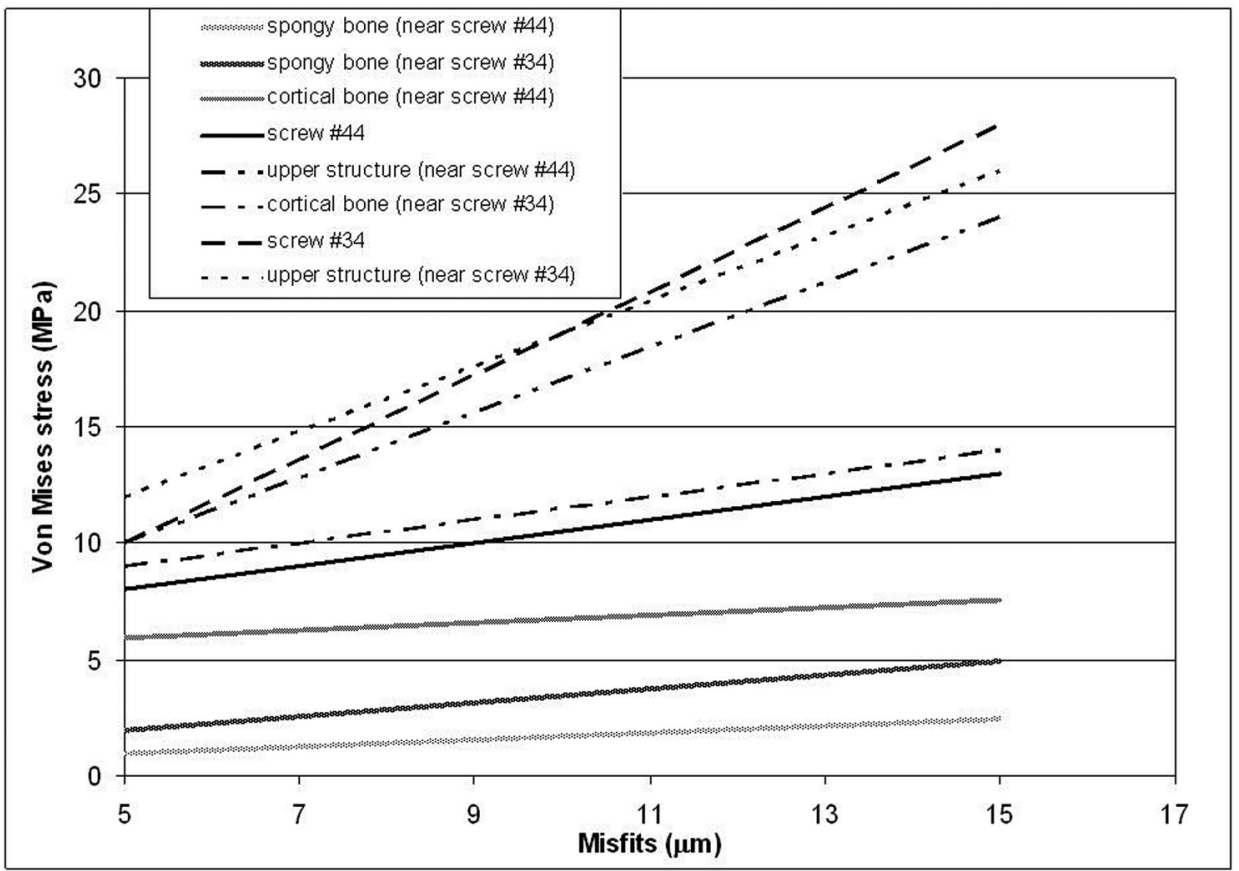

Figure 7. Effects of misfits on stresses.

The stress field in the spongy zone near the final part of the screws in mono-cortical condition has been also investigated. In this zone the stress level is very low but the screws are near the alveolar nerve, located inside the jaw, in the lower zone of the spongy bone. A low but continuous stress level can cause the inflammation of the alveolar nerve $\mathrm{e}^{20)}$. By means of the previous model, it is possible to evaluate the critical zone near the nerve. In all simulated implants, the zone of stresses influence extends to $1.5 \div 2 \mathrm{~mm}$ under the screw, as shown in Figure 8. Under this zone, the amplitude of stresses can be neglected. The results indicate a stress of $0.2 \mathrm{MPa}$ at the top of the screw.

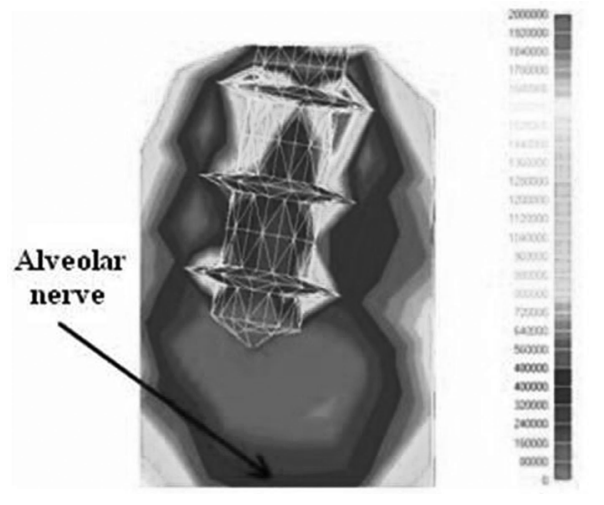

Figure 8. Detail of the stress zone at the tip of a screw.

\section{Discussion}

In order to gain insight in the biomechanics of oral implants, it is crucial to obtain an integrated understanding of the bone behavior around oral implants. Assuming tight contact between the components of the implant system, it is likely that most of the recorded forces will be transferred to the implant. FEA has become an increasingly useful tool for the prediction of the effects of stress on the implant and surrounding bone. A key factor for the success or failure of a dental implant is the manner in which stresses are transferred to surrounding bone. FEA allows investigators to predict stress distribution in the contact area of implants with cortical bone and around the apex of implants in spongy bone.

In this study, a complex prosthesis of dental implants, inserted in a mandible bone, has been analyzed using a virtual model. Masticatory and thermal loads has been analyzed to 
predict stresses concentration in the surrounding bone which has to be taken into account in order to avoid system failure. Moreover, it is known from clinical experience that it is not always possible to place implants into optimal positions. Assembly errors have been simulated in order to investigate the effects of screw heads misfits.

A consistent observation from the current study is the concentration of maximum stress at the bone-implant interface and at the level of cortical bone. The maximum stresses are concentrated in the neck of implant and are probably due to the rigid connection between the implant and bone. The elastic modulus of cortical bone is higher than spongy bone and for this reason cortical bone is stronger and more resistant to deformation. According to the results of the present study, it is suggested that loading an implant with low-volume bone might cause increased stress concentration in the cortical bone. Subsequently, marginal bone reabsorbing might be initiated, if the load capacity of bone is surpassed.

Moreover, according to the results of the numerical investigations an optimization of the shape of the implants has been proposed in order to optimize the assembling procedure. A new kind of the upper part of the screw have been designed to prevent misalignments and to simplify the assembling phase. The alignment of the screws is currently obtained by milling their heads or by mechanical bending of their portion out of the bone. These manual procedures can be harmful for the patient and their success depends on the skills of the dentist.

A possible solution is to manufacture the screw with an adjustable head (cap) that helps in the alignment, as shown in Figure 9.
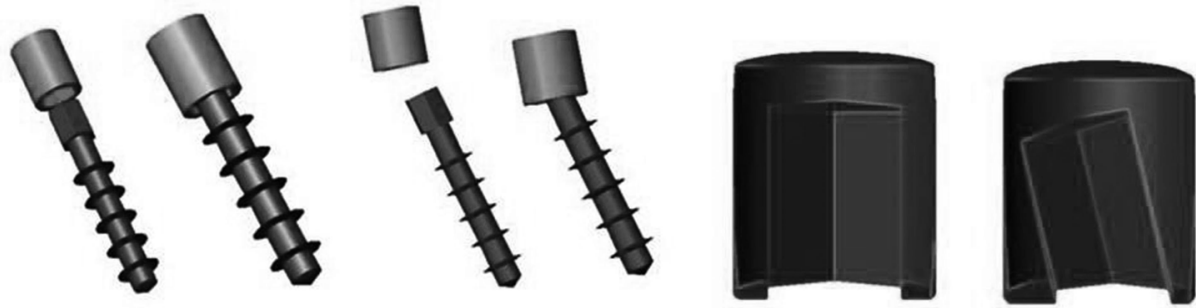

Figure 9. The screws model with different caps (on the left) and sections of the caps (on the right)

The proposed solution is composed of a screw with an hexagonal head (as a simple nut). On this head it is possible to insert different kinds of caps depending on the required inclination of the screw axis. The rigid connection between cap and screw can be obtained with a shrink fit or with adhesive. It is possible to obtain the alignment of screws with different inclination using caps with different angles of the axis of internal hole. Practice shows that the screws are assembled with a maximum misalignment of $20^{\circ}$. A set of 4 caps $\left(5^{\circ}, 10^{\circ}, 15^{\circ}, 20^{\circ}\right)$ can match the possible cases.

In order to investigate the performance of the proposed solution, some analyses have been performed simulating different load conditions. The results show that the stress level occurring in these implants is similar to those of traditional screws, aligned by milling. Moreover, a 30\% reduction of stress level has been observed in comparison to the implants aligned by bending procedure.

All the performed simulations lead to another important consideration about the bridging bar. In fact, when the solution has two or more screws, they are usually connected by an electro welded bar (Figure 10). The function of the bar is to ensure the main stability of the implant during first months, until the osseointegration completes. 

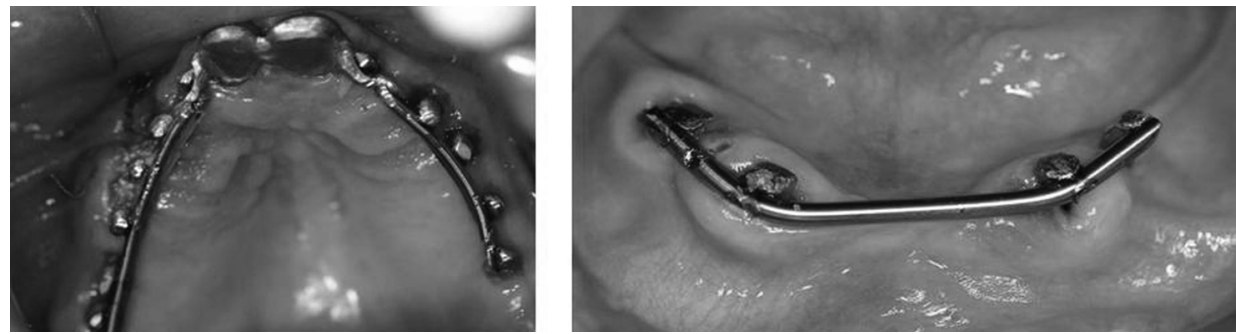

Figure 10. Examples of electro welded bar connecting implants

The bar allows to distribute loads among implants, reducing the peaks of stress levels. When, after some months, the implants are fully osseointegrated, the provisional prosthesis is removed and the permanent one is mounted on. In this phase the presence of the bar makes very difficult the taking of the impression and the assembling of the final prosthesis. For this reason the performances of the system during masticatory phases, with and without bar, have been investigated. The results are summarized in the Figure 11. It can be observed that the structure with bar present a lower level of stress in all the components (bone and implants) before the complete osseointegration.

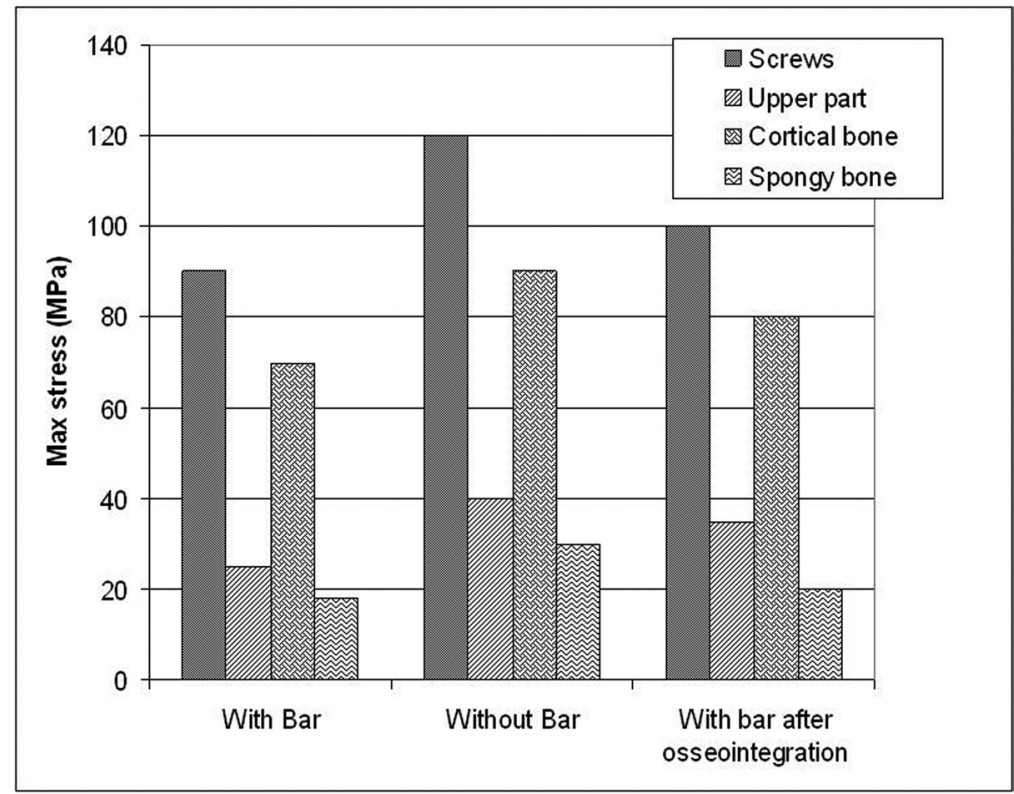

Figure 11. Stresses with and without bar and before and after osseointegration

After the osseointegration, the level of stress in the system without the bar decreases of about 20\%. This result suggests that it is possible to remove the bar after the osseointegration, simplifying the assembling procedure and reducing the risk of assembly errors. Some recent clinical experimentations seem to confirm this observation ${ }^{20,21)}$.

\section{Conclusions}

An accurate virtual model to study the biomechanics of immediate loading implants has been discussed in this paper. The model is based on a detailed description of the geometries and on the simulation of mechanical stresses and deformation by means of finite element technique. It is also been developed starting from a common real case. All the numerical implementations have focused on the interaction between the implant screw and the bone. The presence of masticatory or thermal loads produces a concentration of stresses in the surrounding bone which has to be taken into account by the dentist in order to avoid 
treatment failure and inflammations. These stresses are also caused by distortions and errors which occur during assembling operations. Simulations revealed that the maximum stress in the cortical bone is about $70 \mathrm{MPa}$ in the worst condition (concentrated masticatory loads) using the bridging bar. This value is about the half of the yield strength of an healthy bone tissue $(120 \mathrm{MPa})$. Removing the bar this level of stress increases of $30 \%$ and it is due to a reduced ability of the system to distribute loads among implants. When the osseointegration completes, this increment mitigates of about $20 \%$. In order to simplify the assembling procedure, starting from the numerical results, an innovative modular shape of the implants has been proposed. Simulations demonstrated that in some cases this modification may lead up to a reduction of $30 \%$ considering the stresses due to misfits and misalignments. Although the results are obtained on the specific case, due to the similarity with many restorative solutions, they seems suitable also for generic applications involving immediate loading implants.

\section{Acknowledgements}

The authors wish to acknowledge Dott. Enrico Moglioni and Dott. Paolo Diotallevi for technical discussions and clinical references.

\section{References}

1. Taylor TD, Agar JR, Vogiatzi T. Implant prosthodontics: Current perspective and future directions. Int J Oral Maxillofac Implants, 2000;15:66-75.

2. Binon, P., Sutter F., Beaty K., Brunski J., Gulbransen H., Weiner R. The role of screws in implant systems. International Journal of Oral and Maxillofacial Implants, 1994; 9:49-63.

3. Branemark P.I., Zarb G.A., Albrektsson T., Tissue-integrated prostheses: osseointegration in clinical dentistry, Quintessence, Chicago, 1985, 175-186.

4. Adell R., Eriksson B., Lekholm U., Branemark P.-I., Jempt T., Long-term follow-up study of osseointegrated implants in the treatment of totally edentulous jaws, Int $\mathrm{J}$ Oral Maxillofac Implants, 1990; 5:347-359.

5. Adell R., Lekholm U., Rockler B., Branemark P.I., A 15-year study of osseointegrated implants in the treatment of the edentulous jaw, Int J Oral Surg, 1981; 6:387-416.

6. Chapman R.J., Principles of occlusion for implant prostheses - guidelines for position, timing, and force of occlusal contacts, Quintessence Int, 1989; 20:473-480.

7. Duyck J., Naert I., Van Oosterwyck H., Ronold H.J., Vander Sloten J., Ellingsen J.E., The influence of static and dynamic loading on marginal bone reactions around osseointegrated implants - an animal experimental study, Clin Oral Implants Res, 2001; 12: 207-218.

8. Duyck J, Van Oosterwyck H, Vander Sloten J, De Cooman M, Puers R, Neart I., Magnitude and distribution of occlusal forces on oral implants supporting fixed prostheses: An in vivo study. Clin Oral Implants Res, 2000; 11:465-75.

9. Calvo MP, Muller E, Garg AK. Immediate loading of titanium hexed screw-type implants in the edentulous patient: case report. Implant Dent, 2000; 9:351-7.

10. Salama H, Rose LF, Salama M, Betts NJ. Immediate loading of bilaterally splinted titanium root form implants in fixed prosthodontics: A technique re-examined. Two case reports. Int J Periodontics Restorative Dent, 1994; 15:345-61.

11. U. Meyer, U. Joos, J. Mythili, T. Stamm, A. Hohoff, et al., Ultrastructural characterization of the implant/bone interface of immediately loaded dental implants, Biomaterials, Elsevier, 2004; 25:1959-1967.

12. Ichikawa T., Kanitani H., Kawamato N., Matsumato N., Wigianto R., Influence of bone quality on the stress distribution. An in vitro experiment, Clin Oral Implants Res, 1997; 
8:18-22.

13. Holmes D.C., Loftus J.T., Influence of bone quality on stress distribution for endosseous implants, J Oral Implantol, 1997; 23:104-111.

14. Meijer H.J., Kuiper J.H., Starmans F.J., Bosman F., Stress distribution around the dental implants. Influence of superstructure, length of implants, and height of mandible, J Prosthet Dent, 1992; 68:96-102.

15. Meyer U, Vollmer D, Christoph B, Joos U. Bone loading pattern around implants in average and atrophic edentulous maxillae: A finite-element analysis. J Cranio-Maxillofac Surg 2001; 29:100-5.

16. Isidor F. Loss of osseointegration caused by occlusal load of oral implants. A clinical and radiographic study in monkeys. Clin Oral Implants Res, 1996; 7:143-52.

17. R. A. Jaffin, C. L. Bermen, The excessive loss of Branemark fixtures in type IV bone - a 5-year analysis, J Periodontol, 1991; 62: 2-4.

18. Weinberg L.A., Kruger B., "A comparison of implant/prosthesis loading with four clinical variables", Int J Prosthodont, 1995; 8: 421-433.

19. Pezzuti, E., Diotallevi, P., Moglioni, E., Rastelli, M. "Alterazioni radiologiche del canale mandibolare e aspetti biomeccanici correlati" (in italian), Bullettin of the "Scuola medica ospedaliera”, number 26, 2006.

20. Diotallevi, P. Moglioni, E., Pezzuti, E., Pierazzini, A., Pasqualini, M.E., Floris, P. "Correlazioni biomeccaniche-radiologiche nel riassorbimento osseo perimplantare. Studio comparativo su 47 soggetti” (in italian), DoctorOS, Feb. 2007, pp.117-123.

21. Holmgren E.P., Seckinger R.J., Kilgren L.M., Mante F., Evaluating parameters of osseointegrated dental implants using finite element analysis - a two dimensional comparative study examining the effects of implant diameter, implant shape, and load direction, J Oral Implantol, 1998: 24:80-88.

22. Jeong CM, Caputo AA, Wylie RS, Son SC, Jeon YC. Bicortically stabilized implant load transfer. Int J Oral Maxillofac Implants 2003; 18:59-65.

23. Geng J.P., Tan K.B., Liu G.R., Application of finite element analysis in implant dentistry a review of the literature, J Prosthet Dent, 2001; 85:585-598.

24. Papavasiliou G, Kamposiora P, Bayne SC, Felton DA. Three dimensional finite element analysis of stress distribution around single tooth implants as a function of bony support, prosthesis type and loading during function. J Prosthet Dent, 1996; 76:633-40.

25. Williams K.R., Watson C.J., Murphy W.M., Scott J., Gregory M., Sinobad D., Finite element analysis of fixed prostheses attached to osseointegrated implants, Quintessence Int, 1990; 21: 563-570.

26. Meijer H.J., Starmans F.J., Steen W.H., Bosman F., Loading conditions of endosseous implants in an edentulous human mandible - a three-dimensional, finite-element study, J Oral Rehabil, 1996; 23: 757-763.

27. Ismail YH, Pahountis LN, Fleming JF. Comparison of two-dimensional and three-dimensional finite element analysis of a blade implant. J Oral Implantol, 1987; 4:25-31.

28. DeTolla DH, Andreana S, Patra A, Buhite R, Comella B. The role of the finite element model in dental implants. J Oral Implantol, 2000; 27:77-81.

29. Maduschka, L., Bean spruchung von schrauben verbandungen and zweckkmabige gestaltung der gewindetrager (Stresses in threaded connections and shape optimization). Forschung auf dem gebiete des ingenieeurwesens 7 6: 1936, pp. 229-305.

30. Ashman R.B., Van Buskirk W.C., The elastic properties of a human mandible, Adv Dent Res, 1997; 1:64-67.

31. Brunski JB, Nanci A. Biomaterials and biomechanics of oral and maxillofacial implants: Current status and future developments. Int J Oral Maxillofac Implants, 2000; 15:650-61.

32. Anusavice, KJ, Phillips RW, editors. Phillips' science of dental materials. 11th ed. St Louis: 
Elsevier; 2003.

33. Rangert B., Krogh P.H., Langer B., Van Roekel N., Bending overload and implant fracture-a retrospective clinical analysis,Int J Oral Maxillofac Implants, 1995;10:326-334.

34. T. Kondo, S. Ong, K. Foong, Computer-based extraction of the inferior alveolar nerve canal in 3-D space. Computer Methods and Programs in Biomedicine, 76: 181-191.

35. Tada S, Stegaroiu R, Kitamura E, Miyakawa O, Kusakari H. Influence of implant design and bone quality on stress/strain distribution in bone around implants: A 3-dimensional finite element analysis. Int J Oral Maxillofac Implants 2003; 18:357-68.

36. Teixeira E.R., Sato Y., Akagawa Y., Shindoi N., A comparative evaluation of mandibular finite element models with different lengths and elements for implants biomechanics, J Oral Rehabil, 1998; 25:299-303. 